\title{
Kolaviron and L-Ascorbic Acid Attenuate Chlorambucil-Induced Testicular Oxidative Stress in Rats
}

\author{
Ebenezer Tunde Olayinka and Ayokanmi Ore \\ Biochemistry Unit, Department of Chemical Sciences, Ajayi Crowther University, PMB 1066, Oyo, Oyo State, Nigeria \\ Correspondence should be addressed to Ebenezer Tunde Olayinka; et.olayinka@acu.edu.ng
}

Received 28 May 2014; Revised 14 August 2014; Accepted 4 September 2014; Published 17 September 2014

Academic Editor: Robert H. Rice

Copyright ( 2014 E. T. Olayinka and A. Ore. This is an open access article distributed under the Creative Commons Attribution License, which permits unrestricted use, distribution, and reproduction in any medium, provided the original work is properly cited.

\begin{abstract}
Chlorambucil (4-[4-[bis(2-chloroethyl)amino]phenyl]butanoic acid) is an alkylating agent, indicated in chronic lymphocytic leukaemia. Kolaviron (KV), a biflavonoid complex from Garcinia kola, and L-ascorbic acid (AA) are known to protect against oxidative damage in vivo. This study evaluates the protective capacity of $\mathrm{KV}$ and AA on chlorambucil-induced oxidative stress in the testes of rat. Twenty male Wistar rats $(180-200 \mathrm{~g})$ were randomized into four groups: I: control, II: chlorambucil ( $0.2 \mathrm{mg} / \mathrm{kg}$ b.w.), III: $0.2 \mathrm{mg} / \mathrm{kg}$ chlorambucil and $100 \mathrm{mg} / \mathrm{kg} \mathrm{KV}$, and IV: $0.2 \mathrm{mg} / \mathrm{kg}$ chlorambucil and $100 \mathrm{mg} / \mathrm{kg} \mathrm{AA}$. After 14 days of treatments, results indicated that chlorambucil caused significant reduction $(P<0.05)$ in testicular vitamin $\mathrm{C}$ and glutathione by $32 \%$ and $39 \%$, respectively, relative to control. Similarly, activities of testicular GST, SOD, and CAT reduced significantly by $48 \%$, $47 \%$, and $49 \%$, respectively, in chlorambucil-treated rats relative to control. Testicular MDA and activities of ALP, LDH, and ACP were increased significantly by $53 \%, 51 \%, 64 \%$, and $70 \%$, respectively, in the chlorambucil-treated rat. However, cotreatment with KV and AA offered protection and restored the levels of vitamin $\mathrm{C}, \mathrm{GSH}$, and MDA as well as SOD, CAT, GST, ACP, ALP, and LDH activities. Overall, kolaviron and L-ascorbic acid protected against chlorambucil-induced damage in the testes of the rat.
\end{abstract}

\section{Introduction}

The upsurge in the synthesis and use of anticancer agent has generated questions about the safety of these substances on normal tissues. Most drugs administered in cancer chemotherapy are well known to be associated with toxic side effects [1]. Among the most commonly reported toxic effects are those associated with organs such as the liver, kidneys, testes, and other functional parameters of the blood and immune system [2-6].

Chlorambucil (4-[4-[bis (2-chloroethyl) amino] phenyl] butanoic acid), Figure 1(a), is an orally available alkylating agent indicated in the treatment of chronic leukaemia $[3,7]$. Chlorambucil is rapidly absorbed from the gastrointestinal tract and distributed to the liver, kidneys, and other organs. The metabolism of chlorambucil occurs predominantly in the liver by the hepatic drug metabolising enzymes leading to the formation of 3-(4-dehydrochlorambucil and phenylacetic acid mustard, 2-(4-(bis(2-chloroethyl)amino)phenyl)acetic acid) [8]. Phenylacetic acid mustard is further metabolized to inactive products which are excreted in the urine and faeces [9].

Chlorambucil and its derivatives form covalent bonds with proteins and DNA of neoplastic cells resulting in structural and functional damage to DNA [10]. While chlorambucil and its metabolites are cytotoxic to cancer cells, they may also be toxic to normal body cells. Toxic effects of chlorambucil in the form of haematological toxicity, hepatotoxicity, nephrotoxicity, neurotoxicity, and so forth have been reported $[3,4,11-13]$. Recent study from our laboratory suggested that the mechanism of toxicities elicited by chlorambucil may involve formation of free radicals or depletion of cellular antioxidant reserve [14].

The testes have evolved a formidable antioxidant defence to protect against the damaging effects of free radicals and oxidants which may have negative implication on spermatogenesis [15]. These comprise the nonenzymatic antioxidants including glutathione, ascorbic acid, and tocopherol and 
enzymatic antioxidants such as catalase, superoxide dismutase, glutathione peroxidase, glutathione reductase, and glutathione S-transferase. The testes are rich in lipid components and, therefore, exposure to high level of prooxidants may deplete the antioxidant reserve, thereby exposing the cell to excessive level of lipid peroxidation and ultimately tissue damage [16].

The natural antioxidant, kolaviron, is a fraction of the defatted ethanol extract of Garcinia kola, containing Garcinia biflavonoids GB1 and GB2 and kolaflavanone (Figure 1(c)). Kolaviron is of high safety profile and its antioxidant properties have been extensively studied in vivo [17]. Moreover, it is known to significantly prevent drug and chemical-induced organ toxicity and oxidative damage in experimental animal models $[14,18-20]$.

Many classes of antineoplastic agents are known to generate high levels of oxidative stress in biological systems [21], leading to tissue injuries. Injuries elicited by antineoplastic agents on vital organs have been reported in most cases but with few reports on reproductive organs, particularly the testes. Fewer reports are also available concerning chemotherapy-induced injuries due to generation of potent oxidants or disruptions of testicular antioxidant system by these agents. Besides, proper functioning of the testicular redox homeostasis is essential to efficient spermatogenesis and overall function of the testes. Chlorambucil has been reported in our previous study to induce oxidative stress in the liver of rats [14]. It is assumed that the administration of antioxidants along with chlorambucil may offer some protection against generation of reactive oxygen species (ROS) and oxidative damage to the testes. In addition, if the reactive species and oxidative stress caused by chlorambucil are responsible only for its toxic effects, antioxidants supplementation may reduce the severity of these toxic effects without interfering with the antineoplastic activity of the drug. Evidence suggests that administration of antioxidants along with chemotherapeutic agents has been found to effectively relieve toxic side effects [22-24]. In most cases, antioxidant has improved the cytotoxicity of antineoplastic agents. For instance, vitamin $\mathrm{C}$ is reported to enhance the antineoplastic activity of doxorubicin, cisplatin, and paclitaxil in human breast carcinoma cells [25]. Also, combination of vitamins $\mathrm{A}, \mathrm{C}$, and $\mathrm{E}$ improved the antitumor activity of doxorubicin in mice [26]. Several studies have also reported the potential of the plant derived flavonoids to inhibit the proliferation of cancer cells [27-30]. However, the present study was designed specifically to evaluate the protective role of kolaviron, a biflavonoid complex, and L-ascorbic acid on chlorambucil-induced oxidative stress in the testes of rats.

\section{Materials and Methods}

2.1. Chemicals and Assay Kits. Chlorambucil (Leukeran) was a product of Aspen Pharm Trading Limited, Dublin 1, Ireland. 1-Chloro-2,4-dinitrobenzene (CDNB), 5', $5^{\prime}$-dithiobis-2-nitrobenzoic acid (DTNB), glutathione (GSH), epinephrine, hydrogen peroxide $\left(\mathrm{H}_{2} \mathrm{O}_{2}\right)$, and thiobarbituric acid (TBA) were all purchased from Sigma Chemical Company (London, UK). Assay kits for alkaline phosphatase
(ALP) and acid phosphatase (ACP) were obtained from Randox Laboratories Ltd. (Antrim, UK). Assay kit for lactate dehydrogenase (LDH) was a product of Cypress Diagnostics, Belgium. All other reagents used were of analytical grade and were obtained from British Drug House (BDH), Poole, England.

2.2. Extraction of Kolaviron. Kolaviron was extracted from the fresh seeds of Garcinia kola $(3.5 \mathrm{~kg})$ and characterized according to the method of Iwu et al. [31]. Briefly, the powdered seeds were extracted with light petroleum ether (b.p. $40-60^{\circ} \mathrm{C}$ ) in a Soxhlet extractor for $24 \mathrm{hr}$. The defatted, dried marc was repacked and then extracted with methanol. The extract was concentrated and diluted to twice its volume with distilled water and extracted with ethyl acetate $(6.25 \mathrm{~L})$. The concentrated ethyl acetate fraction yielded a golden yellow solid termed kolaviron which has been shown to consist of Garcinia biflavonoid GB-1 $\left(3^{\prime \prime}, 4^{\prime}, 4^{\prime \prime \prime}, 5,5^{\prime \prime}, 7,7^{\prime \prime}\right.$-heptahydroxy-3, $8^{\prime \prime}$ biflavanone), GB-2 $\left(3^{\prime \prime}, 4^{\prime}, 4^{\prime \prime \prime}, 5,5^{\prime \prime}, 5^{\prime \prime \prime}, 7,7^{\prime \prime}\right.$-octahydroxy-3,8 $8^{\prime \prime}$-biflavanone), and kolaflavanone $\left(3^{\prime \prime}, 4^{\prime}, 4^{\prime \prime \prime}, 5,5^{\prime \prime}, 5^{\prime \prime \prime}, 7,7^{\prime \prime}\right.$ octahydroxy- $4^{\prime \prime \prime}$-methoxy-3,8" -biflavanone) (Figure 1). The purity and identity of kolaviron were determined by subjecting it to thin-layer chromatography (TLC) using Silica gel GF 254-coated plates and solvent mixture of methanol and chloroform in a ratio 1:4 v/v. The separation revealed the presence of three bands which were viewed under UV light at a wavelength of $254 \mathrm{~nm}$ with $\mathrm{RF}$ values of $0.48,0.71$, and 0.76 [32].

2.3. Animal Selection and Care. Twenty inbred male rats (Wistar strain) weighing between 180 and $200 \mathrm{~g}$ were obtained from the animal holding unit of the Department of Chemical Sciences, Ajayi Crowther University, Oyo, Nigeria. The rats were acclimatised under laboratory conditions prior to the commencement of the study. The animals were housed in wire meshed cages maintained at standard conditions of temperature and humidity with an alternating light cycle (12 hr light/dark). They were fed with standard rat pellet (Ladokun feeds, Ibadan, Nigeria) and were supplied water ad libitum. The experimental protocol relating to animal handling conformed to the Guidelines of the National Institute of Health-Guide for the Care and Use of Laboratory Animals (NIH Publication number 85-23 revised 1985: US Department of Health, Education and Welfare Bethesda, MA).

2.4. Drug Treatments. The rats were randomised into four experimental groups (I-IV) of 5 animals each. Group I (control) animals were administered distilled water. Animals in group II received chlorambucil at a dose of $0.2 \mathrm{mg} / \mathrm{kg}$ body weight (b.w.). Group III animals were coadministered chlorambucil ( $0.2 \mathrm{mg} / \mathrm{kg}$ b.w.) and kolaviron (100 mg/kg b.w.). Animals in group IV were coadministered chlorambucil (0.2 mg/kg b.w.) and L-ascorbic acid (100 mg/kg b.w.). The dose of chlorambucil administered to the animals was based on the recommended dose in the treatment of Hodgkin's lymphoma (0.1-0.2 mg/kg/day) [33], while doses of ascorbic acid and kolaviron were selected based on the results obtained 


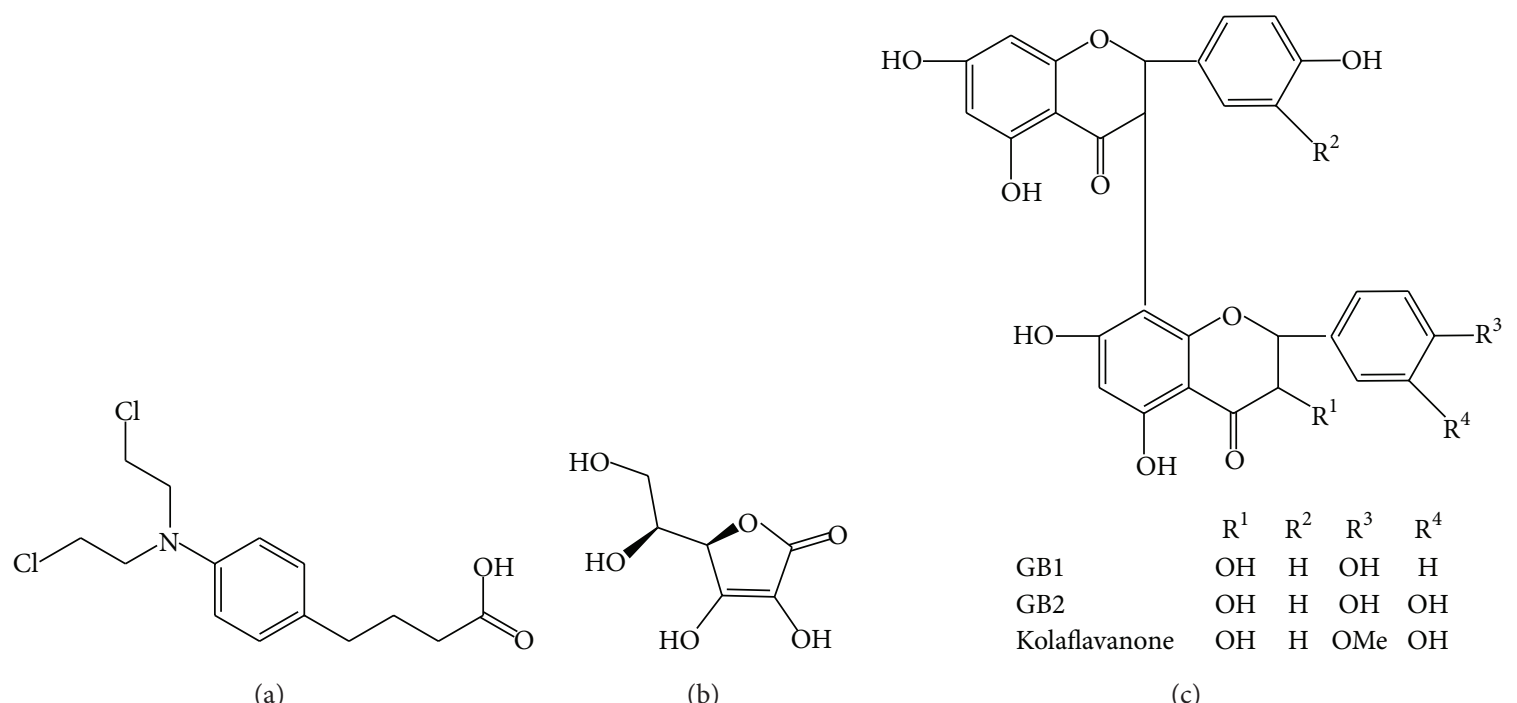

Figure 1: Chemical structure of (a) chlorambucil (4-[4-[bis(2-chloroethyl) amino] phenyl] butanoic acid), (b) L-ascorbic acid, and (c) kolaviron.

from previous studies in experimental animals [34, 35]. Each of the drug doses was delivered orally in $1 \mathrm{~mL}$ solution, once daily using an oral cannula. The vehicle for chlorambucil and ascorbic acid was water while kolaviron was administered in corn oil. This has been included in the revised manuscript and highlighted. All the treatments lasted for a period of 14 days.

2.5. Animal Sacrifice and Collection of Testes. Animals were sacrificed 24 hours after the last treatments by cervical dislocation and the testes were carefully excised from each animal for preparation of cytosolic fraction and histopathological analysis. Testicular samples for histopathological analysis were immediately fixed in Bouin's solution for 24 hours.

2.6. Preparation of Cytosolic Fractions. The testes excised from rats were blotted of blood stains, rinsed in ice-cold $1.15 \% \mathrm{KCl}$, and homogenized in 4 volumes of ice-cold $0.01 \mathrm{M}$ phosphate buffer ( $\mathrm{pH} 7.4)$. The homogenates were centrifuged at $12,500 \mathrm{~g}$ for $15 \mathrm{~min}$ at $-4^{\circ} \mathrm{C}$ (Eppendorf, UK) and the supernatants, termed the postmitochondrial fractions (PMF), were aliquoted and used for biochemical assays.

2.7. Determination of Testicular Protein Content. The protein concentration in the testicular homogenate was determined by the Biuret method of Gornall et al. [36] using bovine serum albumin as standard.

2.8. Assay of Testicular SOD, CAT, and GST. The method of Misra and Fridovich [37] as described by Magwere et al. [38] was used for the determination of testicular superoxide dismutase (SOD) activity by measuring the inhibition of autooxidation of epinephrine at $\mathrm{pH} 10.2$ and $30^{\circ} \mathrm{C}$. Testicular catalase activity was determined by the method of Asru [39] by measuring the reduction of dichromate in acetic acid to chromic acetate at $570 \mathrm{~nm}$. Glutathione S-transferase
(GST) activity was determined by the method described by Habig et al. [40] using 1-chloro-2,4-dinitrobenzene (CDNB) as substrate.

2.9. Assay of Testicular GSH, Ascorbic Acid, and Level of Lipid Peroxidation. Testicular reduced glutathione (GSH) level was determined according to the method of Jollow et al. [41]. The chromophoric product resulting from the reaction of Ellman's reagent with the reduced glutathione, 2-nitro5-thiobenzoic acid, possesses a molar absorption at $412 \mathrm{~nm}$ which was measured in a spectrophotometer. Reduced GSH is proportional to the absorbance at $412 \mathrm{~nm}$. The ascorbic acid concentration was determined according to the method of Jagota and Dani [42]. Ascorbic acid in testicular samples reacts with Folin's reagent, an oxidizing agent to give a blue color which has its maximum absorption at $760 \mathrm{~nm}$. The extent of lipid peroxidation (LPO) was estimated by the method of Varshney and Kale [43]. The method involved the reaction between malondialdehyde (MDA) a product of lipid peroxidation and thiobarbituric acid to yield a stable pink chromophore with maximum absorption at $532 \mathrm{~nm}$.

2.10. Assay of Testicular ACP, ALP, and LDH. Testicular acid phosphatase (ACP), alkaline phosphatase (ALP), and lactate dehydrogenase (LDH) activities were determined using Randox diagnostic kits. ACP and ALP activities were determined by the method of Tietz [44]. The p-nitrophenol formed by the hydrolysis of p-Nitrophenyl phosphate confers yellowish colour on the reaction mixture and its intensity can be monitored at $405 \mathrm{~nm}$ to give a measure of enzyme activity. Determination of testicular LDH activity was based on the method of Cabaud and Wroblewski [45].

2.11. Testicular Histology. The method of Baker and Silverton [46] was employed for the processing of the testicular samples for histopathological studies. Fixed testicular samples were 
dehydrated in graded ethanol and embedded in paraffin wax. A thin section was made from each testicular tissue and was stained with hematoxylin and eosin, followed by examination under a light microscope.

2.12. Statistical Analysis. The results were expressed as mean of 5 replicates \pm SD. Data obtained were subjected to oneway analysis of variance (ANOVA) and complemented with Duncan's multiple range test using SigmaPlot Statistical Software. A value of $P<0.05$ was accepted as statistically significant.

\section{Results}

3.1. Protective Effect of Kolaviron and L-Ascorbic Acid on Chlorambucil-Induced Changes in Testicular SOD, CAT, and GST Activities in Rats. Following two-week exposure to chlorambucil, the testicular activities of SOD, CAT, and GST were significantly decreased by $47 \%, 49 \%$, and $48 \%$, respectively, in chlorambucil-treated animals in comparison with the controls (Table 1). Kolaviron and ascorbic acid cosupplementation with chlorambucil significantly attenuated the activities of these testicular antioxidant enzymes toward the control levels.

\subsection{Protective Effect of Kolaviron and L-Ascorbic Acid on} Chlorambucil-Induced Changes in Testicular Level of GSH, Ascorbic Acid, and MDA in Rats. As presented in Figure 2, a significant decrease by $39 \%$ and $32 \%$ in testicular reduced glutathione and vitamin C (nonenzymic antioxidants) was observed following chlorambucil exposure for two weeks with a corresponding significantly elevated testicular MDA content (a product of lipid peroxidation). However, coadministration of chlorambucil with kolaviron and vitamin $\mathrm{C}$ acid, respectively, significantly ameliorated the decrease in testicular GSH, vitamin C and increase in MDA (Figure 2).

3.3. Protective Effect of Kolaviron and L-Ascorbic Acid on Chlorambucil-Induced Changes in Activities of Testicular ACP, $A L P$, and $L D H$. The testicular acid phosphatase (ACP) activity (Figure 3(a)) was significantly reduced by $70 \%$ while alkaline phosphatase (ALP) and lactate dehydrogenase (LDH) activities showed a significant increase by $59 \%$ and $64 \%$, respectively, in the chlorambucil-treated animals with respect to the control (Figures 3(a), 3(b), and 3(c)). Kolaviron or ascorbic acid cosupplementation with chlorambucil significantly restored the activities of these testicular enzymes toward control.

3.4. Protective Role of Kolaviron and L-Ascorbic Acid against Chlorambucil-Induced Damage to Testicular Histology. Representative photomicrographs of the testicular sections from rats are shown in Figure 4. The histological study of the testicular section of the control rats showed a typical normal cellular architecture with no lesion. However, chlorambucil exposure for two weeks resulted in formation of immature germinal cells in the lumen (Figure 4(b)). However, coadministration of chlorambucil with kolaviron and ascorbic acid restored the testicular histoarchitecture with distinct cellular arrangements as observed for control animals.

\section{Discussion}

This study investigated the protective role of orally administered kolaviron and ascorbic acid in chlorambucil-induced testicular toxicity in rat. Chlorambucil is an anticancer agent indicated for chronic leukaemia and may have the capacity to induce oxidative stress or deplete tissue antioxidant reserve during chemotherapy [14]. The testis is an organ involved in spermatogenesis and is normally exposed to a low oxygen level. Despite the low oxygen level, the testes are known to be vulnerable to oxidative stress and peroxidative damage, due to the abundance of highly unsaturated fatty acids [15]. Testicular oxidative stress plays an important role in conditions known to be detrimental to male fertility. These conditions include exposure to certain drugs and environmental toxicants. Series of studies on antineoplastic agents have shown that they can cause oxidative stress in the testes with resulting disturbance in testicular functions [6,47]. However, the testes possess formidable antioxidant defence systems comprising both enzymatic and nonenzymatic antioxidants. The enzymatic constituents of this defence system are made up of catalase (CAT), superoxide dismutase (SOD), glutathione Stransferase (GST), and glutathione peroxidase (GPx). The nonenzymatic constituents include the ascorbic acid (AA), reduced glutathione (GSH), and vitamin $\mathrm{E}$.

In this study, we observed a significant reduction in testicular activities of superoxide dismutase (SOD), catalase (CAT), and glutathione S-transferase as a result of CLB administration. SOD catalyzes the reaction involving a rapid dismutation of superoxide radical to hydrogen peroxide and dioxygen while CAT converts the hydrogen peroxide formed in this process and other cellular processes into water and molecular oxygen. Reduction in the activities of SOD and CAT by chlorambucil may predispose the testes to oxidative damage [47]. Glutathione S-transferase (GST), on the other hand, is an enzyme involved in the detoxification of ingested xenobiotics in the liver. GST activity is also present in other tissues including the testes where it functions as part of the antioxidant defense mechanism that scavenge and suppress the formation of ROS [48]. In addition to the formation of glutathione S-conjugates of drugs, GST also possesses antioxidant capabilities. It catalyses the reduction of peroxidecontaining compounds in the cell and this peroxidase activity exhibited by GST is however dependent on availability of GSH [48]. Coadministration of kolaviron and L-ascorbic acid offers protection against oxidative stress in the testes of the animal by increasing the activities of antioxidant enzymes in the experimental animals.

AA is a vital antioxidant of the aqueous phase of the cell and rapidly scavenges free radicals. It also plays an important role in the regeneration of vitamin $\mathrm{E}$ - the membrane bound antioxidant [49]. The AA in the testes is maintained in a reduced state by GSH dependent dehydroascorbate reductase in the testes. Suppression of testicular AA and GSH following administration of antineoplastic drugs has been reported 
TABLE 1: Protective effect of kolaviron and L-ascorbic acid on chlorambucil-induced changes in testicular SOD, CAT, and GST activities in rats.

\begin{tabular}{|c|c|c|c|}
\hline Treatment groups & SOD (units) & CAT $(\mu$ moles $/ \mathrm{min} / \mathrm{mg}$ protein $)$ & GST (nmole/min/mg protein) \\
\hline Control & $38.6 \pm 1.9$ & $8.14 \pm 0.1$ & $18.8 \pm 1.2$ \\
\hline CLB & $20.4 \pm 1.8^{*}$ & $4.12 \pm 0.3^{*}$ & $9.74 \pm 0.8^{*}$ \\
\hline $\mathrm{CLB}+\mathrm{KV}$ & $34.0 \pm 1.6^{* \dagger}$ & $7.14 \pm 0.2^{* \dagger}$ & $17.14 \pm 0.9^{* \dagger}$ \\
\hline $\mathrm{CLB}+\mathrm{AA}$ & $32.8 \pm 2.5^{* \dagger}$ & $7.60 \pm 0.4^{* \dagger}$ & $16.0 \pm 1.1^{* \dagger}$ \\
\hline
\end{tabular}

Results are expressed as mean \pm S.D $(n=5)$; SOD: superoxide dismutase, CAT: catalase, GST: glutathione S-transferase, CLB: chlorambucil (0.2 mg/Kg b.w.), KV: kolaviron (100 mg/Kg b.w.), and AA: ascorbic acid (100 mg/Kg b.w.). ${ }^{*}$ Significantly different from control; ${ }^{\dagger}$ Significantly different from CLB.

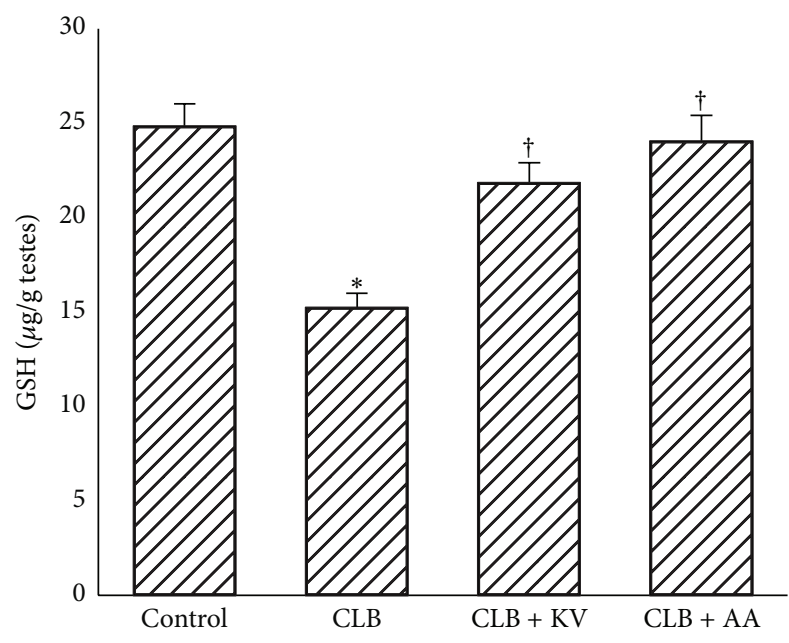

(a)

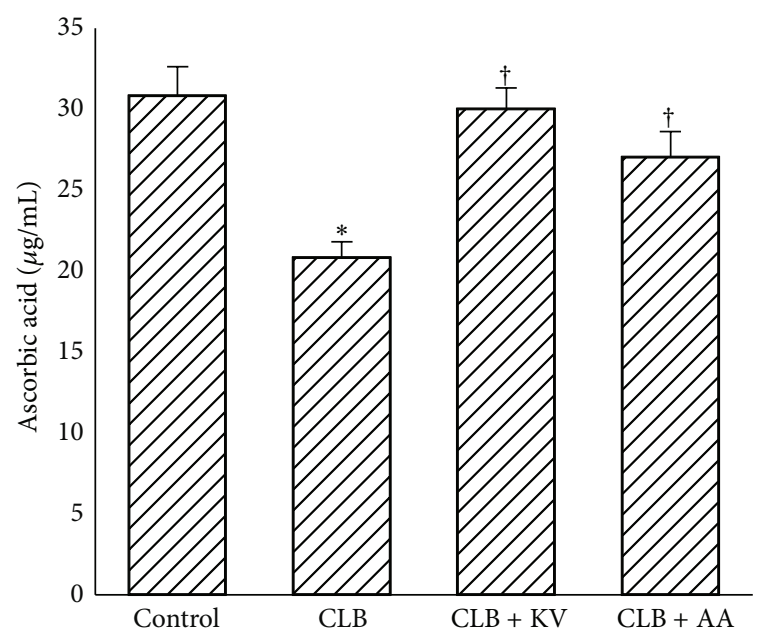

(b)

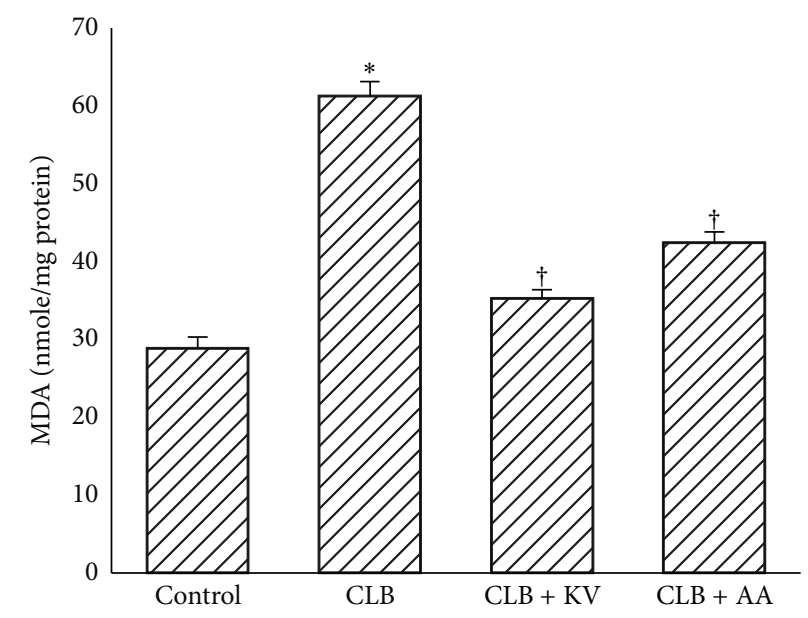

(c)

FIGURE 2: Protective effect of kolaviron and L-ascorbic acid on chlorambucil-induced changes in testicular level of GSH, ascorbic acid, and MDA in rats. Results are expressed as mean \pm S.D $(n=5)$; GSH: reduced glutathione, MDA: malondialdehyde, CLB: chlorambucil (0.2 mg/Kg b.w.), KV: kolaviron (100 mg/Kg b.w.), and AA: ascorbic acid (100 mg/Kg b.w.). ${ }^{*}$ Significantly different from CTRL; ${ }^{\dagger}$ Significantly different from CLB.

in several studies $[50,51]$. The observed reduction may be caused by the presence of free radicals generated during the metabolism of the drug, resulting in the consumption of the available AA and GSH in the testes. Reduction in testicular activities of enzymatic and levels of nonenzymatic antioxidants can predispose the testes to excessive oxidative stress. Suppression of testicular antioxidant system has been widely associated with oxidative stress. Uncontrolled oxidative stress may result in membrane lipid peroxidation and, ultimately, testicular damage and loss of testicular functions. The decrease in the activities of SOD, CAT, and GST in CLBexposed rat testicular cells may have increased the observed level of lipid peroxidation. This observation is consistent with previous reports [52-54]. The observed reduction in 


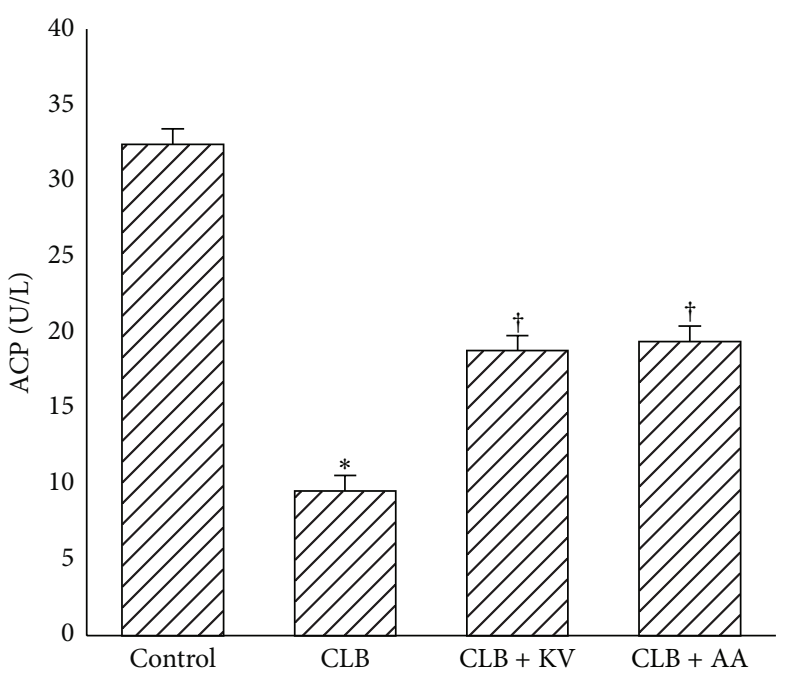

(a)

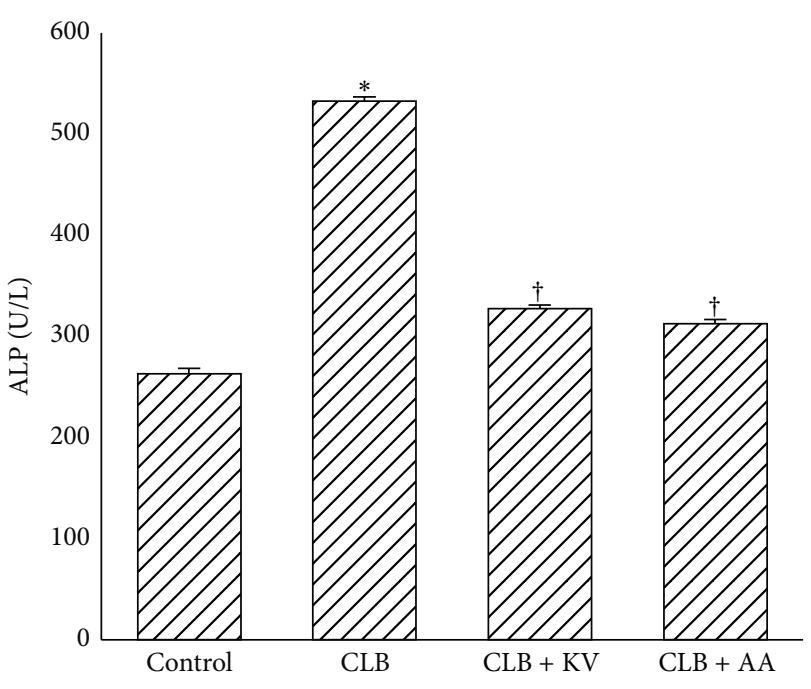

(b)

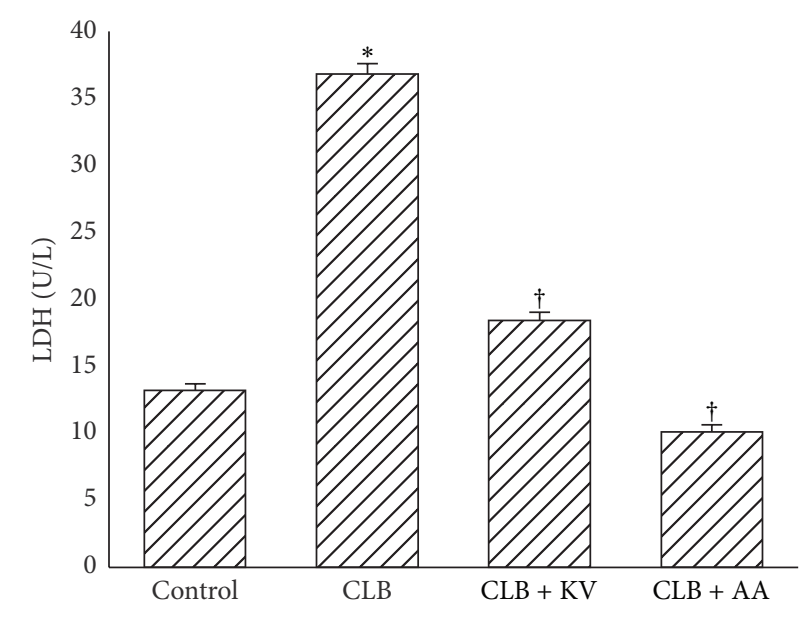

(c)

FIGURE 3: Protective effect of kolaviron and L-ascorbic acid on chlorambucil-induced changes in testicular ACP, ALP, and LDH in rats. Results are expressed as mean \pm S.D $(n=5)$; ACP: acid phosphatase, ALP: alkaline phosphatase, LDH: lactate dehydrogenase, CLB: chlorambucil (0.2 mg/Kg b.w.), KV: kolaviron (100 mg/Kg b.w.), and AA: ascorbic acid (100 mg/Kg b.w.). ${ }^{*}$ Significantly different from CTRL; ${ }^{\dagger}$ Significantly different from CLB.

testicular lipid peroxidation may be related to the protection of the antioxidant defense system in the rats by kolaviron and AA [55].

Activities of testicular marker enzymes such as acid phosphate (ACP), alkaline phosphate (ALP), and lactate dehydrogenase $(\mathrm{LDH})$ are considered functional indicators of spermatogenesis. The reduction in the activity of ACP by the administration of CLB was supported by Ananthan and Kumaran [56] where administration of Mancozeb (a fungicide of ethylene-bis-dithiocarbamate group) significantly decreased the activity of ACP in the testis of rat. Spermatogenic cells contain acid phosphatase and the specific activity of this enzyme increases as the germ cells differentiate from spermatogonia into spermatocytes and spermatids [57]. Lysosomal acid phosphatases also participate in the intracellular digestion of endogenous and phagocytosed exogenous compounds containing phosphate residues. In the acrosome, they may be involved in the penetration of the spermatozoon through the egg [57]. The increase in the activity of ACP in the testes of animals administered KV and AA may be related to increased lysosomal activity in the testes. ALP and LDH play an important role in the process of spermatogenesis and have been shown to be vital for sperm survival and motility [58]. The increased activity of testicular ALP and LDH observed in this study may reflect testicular degeneration [53]. LDH is closely associated with spermatogenesis and testicular development. Increase in the activity of this enzyme in the chlorambucil-treated rats may also be resulting from adaptation to improve spermatogenesis and testicular development from oxidative damage [59]. KV and AA effectively attenuated the activities of ACP, ALP, and LDH.

The degeneration of testicular histological structure by CLB may be a result of oxidative damage. This can also result 


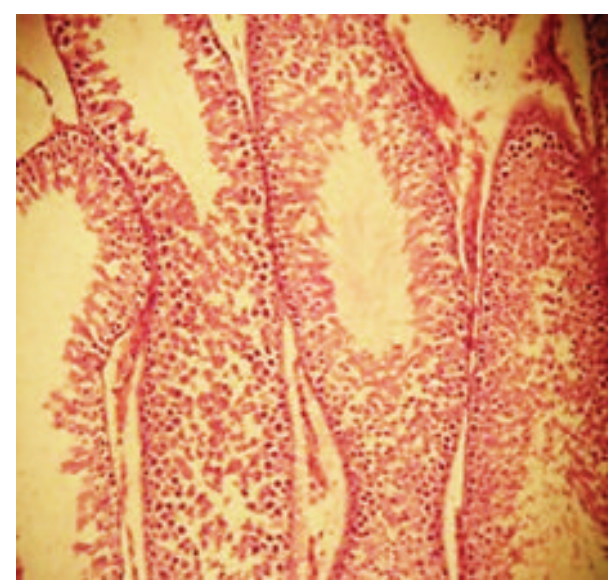

(a)

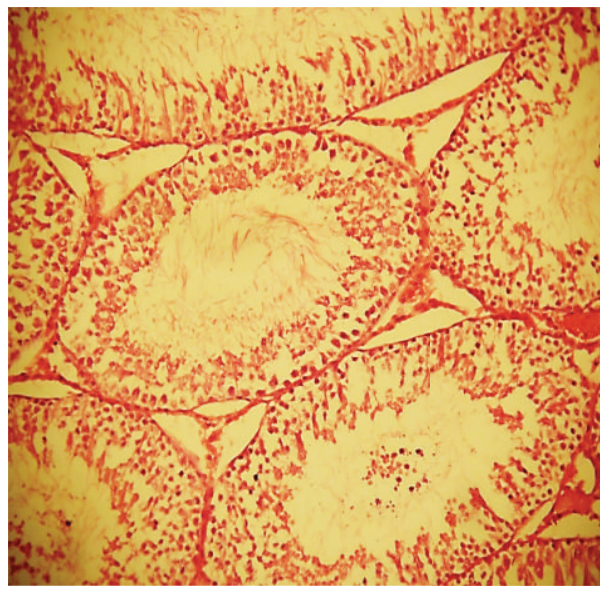

(c)

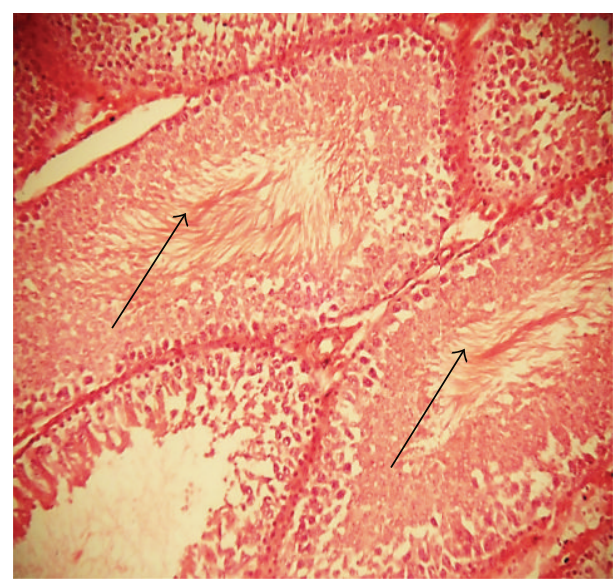

(b)

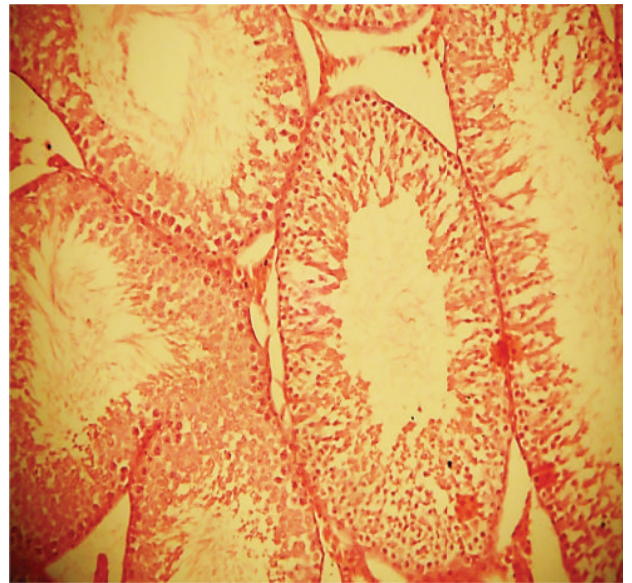

(d)

FIGURE 4: Photomicrograph showing protective role of kolaviron and L-ascorbic acid on chlorambucil-induced damage on testicular morphology (hematoxylin and eosin stain). (a) Control: no visible lesions seen. (b) Chlorambucil group: there are immature germinal cells in the lumen. (c) Chlorambucil + kolaviron group: no visible lesions seen; (d) chlorambucil + ascorbic acid group: no visible lesions seen.

in the degeneration of germ cells and poor sperm quality [60]. $\mathrm{KV}$ and AA supplementation prevented the degeneration of germ cells as evidenced by histological evaluation. Potential evidences from the literature, supporting the role of ROSmediated oxidative stress, may be responsible for the mechanism of chlorambucil-induced testicular toxicity observed [14]. The observed attenuation properties of $\mathrm{KV}$ and $\mathrm{AA}$ in this study may be due to their antioxidant properties [23, 61], which may be involved in the scavenging of radical species generated by CLB.

\section{Conclusion}

From our present study, it may be suggested that chlorambucil impairs testicular antioxidant system and causes degenerative changes in the germ cells. However, kolaviron and ascorbic acid positively modulate the effect of the drug on the antioxidant status and effectively prevent chlorambucilinduced testicular toxicity.

\section{Conflict of Interests}

The authors declare that there is no conflict of interests regarding the publication of this paper.

\section{References}

[1] N. Vardi, H. Parlakpinar, B. Ates, A. Cetin, and A. Otlu, "Antiapoptotic and antioxidant effects of $\beta$-carotene against methotrexate-induced testicular injury," Fertility and Sterility, vol. 92, no. 6, pp. 2028-2033, 2009.

[2] P. E. Kintzel and R. T. Dorr, "Anticancer drug renal toxicity and elimination: dosing guidelines for altered renal function," Cancer Treatment Reviews, vol. 21, no. 1, pp. 33-64, 1995.

[3] J. Tomenendalova, J. Mayer, M. Doubek, D. Horky, K. Rehakova, and J. Doubek, "Chlorambucil and fludarabine as a new pretransplant conditioning for patients with chronic lymphocytic leukemia: results of in vivo experiments," Veterinarni Medicina, vol. 53, no. 10, pp. 564-571, 2008. 
[4] G. Pearse, A. Pietersma, J. Cunliffe et al., "Time-course study of the immunotoxic effects of the anticancer drug chlorambucil in the rat," Toxicologic Pathology, vol. 37, no. 7, pp. 887-901, 2009.

[5] G. Ramadori and S. Cameron, "Effects of systemic chemotherapy on the liver," Annals of Hepatology, vol. 9, no. 2, pp. 133-143, 2010.

[6] E. Yuluğ, S. Türedi, A. Alver, and C. Kahraman, "Effects of resveratrol on methotrexate-induced testicular damage in rats," The Scientific World Journal, vol. 2013, Article ID 489659, 6 pages, 2013.

[7] G. C. Kundu, J. R. Schullek, and I. B. Wilson, "The alkylating properties of chlorambucil," Pharmacology Biochemistry and Behavior, vol. 49, no. 3, pp. 621-624, 1994.

[8] A. McLean, D. Newell, G. Baker, and T. Connors, "The metabolism of chlorambucil," Biochemical Pharmacology, vol. 29, no. 14, pp. 2039-2047, 1980.

[9] D. Plumb, Plumb's Veterinary Drug Handbook, Blackwell, Stockholm, Wis, USA, 2005.

[10] A. Pućkowska, D. Drozdowska, M. Rusak, T. Bielawski, I. Bruzgo, and K. Midura-Nowaczek, "Amino and chlorambucil analogues of pentamidine: synthesis and biological examinations," Acta Poloniae Pharmaceutica: Drug Research, vol. 69, no. 1, pp. 63-73, 2012.

[11] N. Pichon, M. Debette-Gratien, F. Cessot et al., "Acute cholestatic hepatitis due to chlorambucil," Gastroenterologie Clinique et Biologique, vol. 25, no. 2, pp. 202-203, 2001.

[12] A. Nicolle, S. J. Proctor, and G. P. Summerfield, "High dose chlorambucil in the treatment of lymphoid malignancies," Leukemia and Lymphoma, vol. 45, no. 2, pp. 271-275, 2004.

[13] N. Lameire, V. Kruse, and S. Rottey, "Nephrotoxicity of anticancer drugs-an underestimated problem?" Acta Clinica Belgica, vol. 66, no. 5, pp. 337-345, 2011.

[14] E. T. Olayinka, A. Ore, and K. A. Fashiku, "Kolaviron and Lascorbic acid ameliorates chlorambucil-induced hepatic and renal toxicity in rat," International Journal of Toxicology and Applied Pharmacology, vol. 4, no. 1, pp. 23-32, 2014.

[15] R. J. Aitken and S. D. Roman, "Antioxidant systems and oxidative stress in the testes," in Molecular Mechanism in Spermatogenesis, C. Y. Cheng, Ed., pp. 154-171, Landes Bioscience and Springer Science, 2008.

[16] C. Mylonas and D. Kouretas, "Lipid peroxidation and tissue damage," In Vivo, vol. 13, no. 3, pp. 295-309, 1999.

[17] E. O. Farombi, I. A. Adedara, A. B. Oyenihi, E. Ekakitie, and S. Kehinde, "Hepatic, testicular and spermatozoa antioxidant status in rats chronically treated with Garcinia kolaseed," Journal of Ethnopharmacology, vol. 146, no. 2, pp. 536-542, 2013.

[18] E. O. Farombi, I. A. Adedara, S. A. Akinrinde, O. O. Ojo, and A. S. Eboh, "Protective effects of kolaviron and quercetin on cadmium-induced testicular damage and endocrine pathology in rats," Andrologia, vol. 44, no. 4, pp. 273-284, 2012.

[19] I. A. Adedara, P. P. Mathur, and E. O. Farombi, "Kolaviron prevents ethylene glycol monoethyl ether-induced testicular apoptosis via down-regulation of stress proteins, Fas/Fas-L and caspases expressions in rats," Toxicology Mechanisms and Methods, vol. 23, no. 9, pp. 689-696, 2013.

[20] O. A. Adaramoye, O. O. Akanni, and E. O. Farombi, "Nevirapine induces testicular toxicity in Wistar rats: reversal effect of kolaviron (biflavonoid from Garcinia kola seeds)," Journal of Basic and Clinical Physiology and Pharmacology, vol. 24, no. 4, pp. 313-320, 2013.
[21] K. A. Conklin, "Chemotherapy-associated oxidative stress: impact on chemotherapeutic effectiveness," Integrative Cancer Therapies, vol. 3, no. 4, pp. 294-300, 2004.

[22] J. A. Drisko, J. Chapman, and V. J. Hunter, "The use of antioxidant therapies during chemotherapy," Gynecologic Oncology, vol. 88, no. 3, pp. 434-439, 2003.

[23] S. M. Sagar, "Should patients take or avoid antioxidant supplements during anticancer therapy? An evidence-based review," Current Oncology, vol. 12, no. 2, pp. 44-54, 2005.

[24] A. M. Seufi, S. S. Ibrahim, T. K. Elmaghraby, and E. E. Hafez, "Preventive effect of the flavonoid,quercetin, on hepatic cancer in rats via oxidant/antioxidant activity: molecular and histological evidences," Journal of Experimental and Clinical Cancer Research, vol. 28, no. 1, article 80, 2009.

[25] C. M. Kurbacher, U. Wagner, B. Kolster, P. E. Andreotti, D. Krebs, and H. W. Bruckner, "Ascorbic acid (vitamin C) improves the antineoplastic activity of doxorubicin, cisplatin, and paclitaxel in human breast carcinoma cells in vitro," Cancer Letters, vol. 103, no. 2, pp. 183-189, 1996.

[26] V. S. Mosienko, L. T. Khasanova, V. N. Sukolinskii, T. S. Morozkina, and V. N. Sukolinskiu, "Abstract Effectiveness of combined action of vitamins A, E, and C and Cyclophosphane or Adriamycin on growth of transpslanted tumors in mice," Eksperimentalaia Oncologiia, vol. 12, pp. 55-57, 1990.

[27] J. A. Choi, J. Y. Kim, J. Y. Lee et al., "Induction of cell cycle arrest and apoptosis in human breast cancer cells by quercetin," International Journal of Oncology, vol. 19, no. 4, pp. 837-844, 2001.

[28] C. S. Ong, E. Tran, T. T. T. Nguyen et al., "Quercetin-induced growth inhibition and cell death in nasopharyngeal carcinoma cells are associated with increase in Bad and hypophosphorylated retinoblastoma expressions," Oncology Reports, vol. 11, no. 3, pp. 727-733, 2004.

[29] R. G. Beniston and M. S. Campo, "Quercetin elevates p27Kip1 and arrests both primary and HPV16 E6/E7 transformed human keratinocytes in G1," Oncogene, vol. 22, no. 35, pp. 55045514, 2003.

[30] G. Di Carlo, N. Mascolo, A. A. Izzo, and F. Capasso, "Flavonoids: old and new aspects of a class of natural therapeutic drugs," Life Sciences, vol. 65, no. 4, pp. 337-353, 1999.

[31] M. M. Iwu, O. A. Igboko, C. O. Okunji, and M. S. Tempesta, "Antidiabetic and aldose reductase activities of biflavanones of Garcinia kola," Journal of Pharmacy and Pharmacology, vol. 42, no. 4, pp. 290-292, 1990.

[32] O. A. Adaramoye, E. O. Farombi, E. O. Adeyemi, and G. O. Emerole, "Comparative study on the antioxidant properties of flavonoids of Garcinia kola seeds," Pakistan Journal of Medical Sciences, vol. 21, no. 3, pp. 331-339, 2005.

[33] J. Tomenendálová, J. Mayer, M. Doubek et al., "Toxicity of highdose chlorambucil in Wistar rats," Acta Veterinaria Brno, vol. 77, no. 4, pp. 595-602, 2008.

[34] E. O. Farombi and I. A. Nwaokeafor, "Anti-oxidant mechanisms of kolaviron: Studies on serum lipoprotein oxidation, metal chelation and oxidative membrane damage in rats," Clinical and Experimental Pharmacology and Physiology, vol. 32, no. 8, pp. 667-674, 2005.

[35] S. O. Malomo, A. Ore, and M. T. Yakubu, "In vitro and in vivo antioxidant activities of the aqueous extract of Celosia argentea leaves," Indian Journal of Pharmacology, vol. 43, no. 3, pp. 278285, 2011. 
[36] A. G. Gornall, C. J. Bardwawill, and M. M. David, "Determination of serum proteins by means of the biuret reaction," The Journal of biological chemistry, vol. 177, no. 2, pp. 751-766, 1949.

[37] H. P. Misra and I. Fridovich, "The role of superoxide anion in the autoxidation of epinephrine and a simple assay for superoxide dismutase," The Journal of Biological Chemistry, vol. 247, no. 10, pp. 3170-3175, 1972.

[38] T. Magwere, Y. S. Naik, and J. A. Hasler, "Effects of chloroquine treatment on antioxidant enzymes in rat liver and kidney," Free Radical Biology and Medicine, vol. 22, no. 1-2, pp. 321-327, 1996.

[39] A. K. Sinha, "Colorimetric assay of catalase," Analytical Biochemistry, vol. 47, no. 2, pp. 389-394, 1972.

[40] W. H. Habig, M. J. Pabst, and W. B. Jakoby, "Glutathione $\mathrm{S}$ transferases. The first enzymatic step in mercapturic acid formation," Journal of Biological Chemistry, vol. 249, no. 22, pp. 7130-7139, 1974.

[41] D. J. Jollow, J. R. Mitchell, N. Zampaglione, and J. R. Gillette, "Bromobenzene induced liver necrosis. Protective role of glutathione and evidence for 3,4 bromobenzene oxide as the hepatotoxic metabolite," Pharmacology, vol. 11, no. 3, pp. 151$169,1974$.

[42] S. K. Jagota and H. M. Dani, "A new colorimetric technique for the estimation of vitamin C using folin phenol reagent," Analytical Biochemistry, vol. 127, no. 1, pp. 178-182, 1982.

[43] R. Varshney and R. K. Kale, "Effects of calmodulin antagonists on radiation-induced lipid peroxidation in microsomes," International Journal of Radiation Biology, vol. 58, no. 5, pp. 733-743, 1990.

[44] N. M. Tietz, Clinical Guide to Laboratory Tests, Saunders, Philadelphia, Pa, USA, 3rd edition, 1995.

[45] P. G. Cabaud and F. Wroblewski, "Colorimetric measurement of lactic dehydrogenase activity of body fluids," The American Journal of Clinical Pathology, vol. 30, no. 3, pp. 234-236, 1958.

[46] F. J. Baker and R. E. Silverton, Introduction to Medical Laboratory Technology, Butter worth, London, UK, 6th edition, 1985.

[47] J. Yeh, B. S. Kim, and J. Peresie, "Reproductive toxic effects of cisplatin and its modulation by the antioxidant sodium 2mercaptoethanesulfonate (Mesna) in female rats," Reproductive Biology Insights, vol. 4, no. 1, pp. 17-27, 2011.

[48] P. J. Sherratt and J. D. Hayes, "Glutathione S-transferases," in Enzyme Systems that Metabolise Drugs and Other Xenobiotics, C. Ioannides, Ed., pp. 219-252, John Wiley \& Sons, London, UK, 2002.

[49] K. M. Robert, K. G. Daryl, A. M. Peter, and W. R. Victor, "Vitamins and Minerals," in Harper's Biochemistry, R. K. Murray, D. K. Granner, P. A. Mayes, and V. W. Rodwell, Eds., vol. 25, pp. 169-649, Appleton Lange, New York, NY, USA, 2000.

[50] Y. O. Ilbey, E. Ozbek, A. Simsek, A. Otunctemur, M. Cekmen, and A. Somay, "Potential chemoprotective effect of melatonin in cyclophosphamide- and cisplatin-induced testicular damage in rats," Fertility and Sterility, vol. 92, no. 3, pp. 1124-1132, 2009.

[51] L. Patil and R. Balaraman, "Effect of melatonin on doxorubicin induced testicular damage in rats," International Journal of PharmTech Research, vol. 1, no. 3, pp. 879-884, 2009.

[52] E. T. Olayinka, A. Ore, and O. O. Akinnawo, "Protective role of ethanolic extract of Sorghum bicolor leaf sheath against cadmium-induced oxidative stress in rats," International Journal of Pharmacology Biomedical Research, vol. 2, no. 4, pp. 254-260, 2011.

[53] P. Seema, S. S. Swathy, and M. Indira, "Protective effect of selenium on nicotine-induced testicular toxicity in rats," Biological Trace Element Research, vol. 120, no. 1-3, pp. 212-218, 2007.
[54] K. Jana, P. K. Samanta, and D. Kumar De, "Nicotine diminishes testicular gametogenesis, steroidogenesis, and steroidogenic acute regulatory protein expression in adult albino rats: possible influence on pituitary gonadotropins and alteration of testicular antioxidant status," Toxicological Sciences, vol. 116, no. 2, pp. 647-659, 2010.

[55] O. A. Adaramoye and M. Arisekola, "Kolaviron, a biflavonoid complex from Garcinia kola seeds, ameliorates ethanol-induced reproductive toxicity in male wistar rats," Nigerian Journal of Physiological Sciences, vol. 28, no. 1, pp. 9-15, 2012.

[56] G. Ananthan and B. Kumaran, "Effect of mancozeb on the specific activities of testicular phosphatases and Protective role of vitamin C in Albino rats," Bullettin of Environmental Pharmacology and Life Sciences, vol. 2, no. 7, pp. 56-61, 2013.

[57] T. Vanha-Perttula, J. P. Mather, C. W. Bardin, S. B. Moss, and A. R. Bellvé, "Acid phosphatases in germinal and somatic cells of the testes.," Biology of reproduction, vol. 35, no. 1, pp. 1-9, 1986.

[58] P. Kaur and M. P. Bansal, "Influence of selenium induced oxidative stress on spermatogenesis and lactate dehydrogenase$\mathrm{X}$ in mice testis," Asian Journal of Andrology, vol. 6, no. 3, pp. 227-232, 2004.

[59] S. O. Abarikwu, E. O. Farombi, and A. B. Pant, "Kolaviron biflavanoids of garcinia kola seeds protect atrazine-induced cytotoxicity in primary cultures of rat leydig cells," International Journal of Toxicology, vol. 31, no. 4, pp. 407-415, 2012.

[60] S. Kim, I. Lee, H. Baek, C. Moon, S. Kim, and J. Kim, "Protective effect of diallyl disulfide on cyclophosphamideinduced testicular toxicity in rats," Laboratory Animal Research, vol. 29, no. 4, pp. 204-211, 2013.

[61] K. Iqbal, A. A. Khan, and K. K. Khattak, "Biological significance of ascorbic acid (vitamin C) in human health: a review," Pakistan Journal of Nutrition, vol. 3, no. 1, pp. 5-13, 2004. 

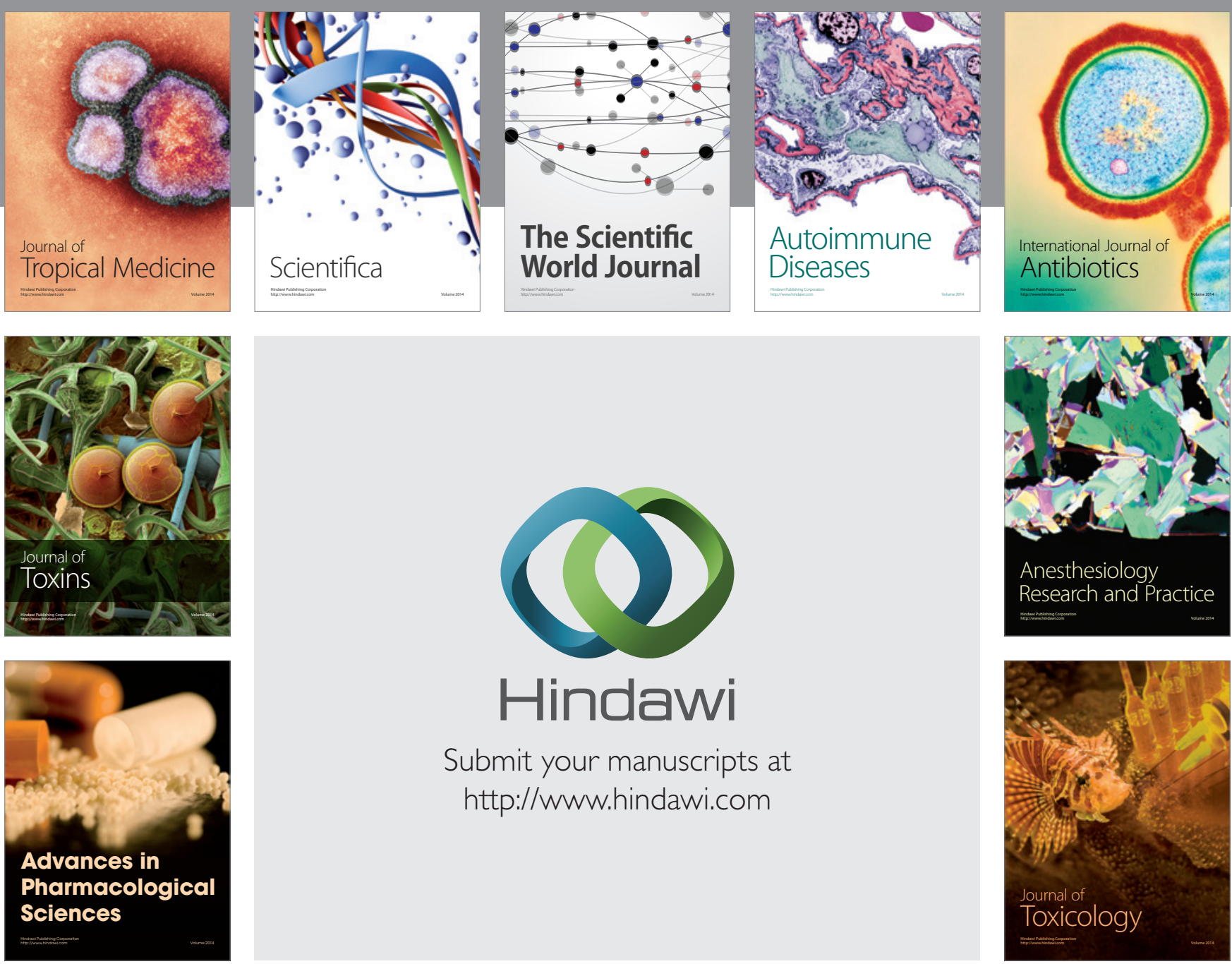

\section{Hindawi}

Submit your manuscripts at

http://www.hindawi.com
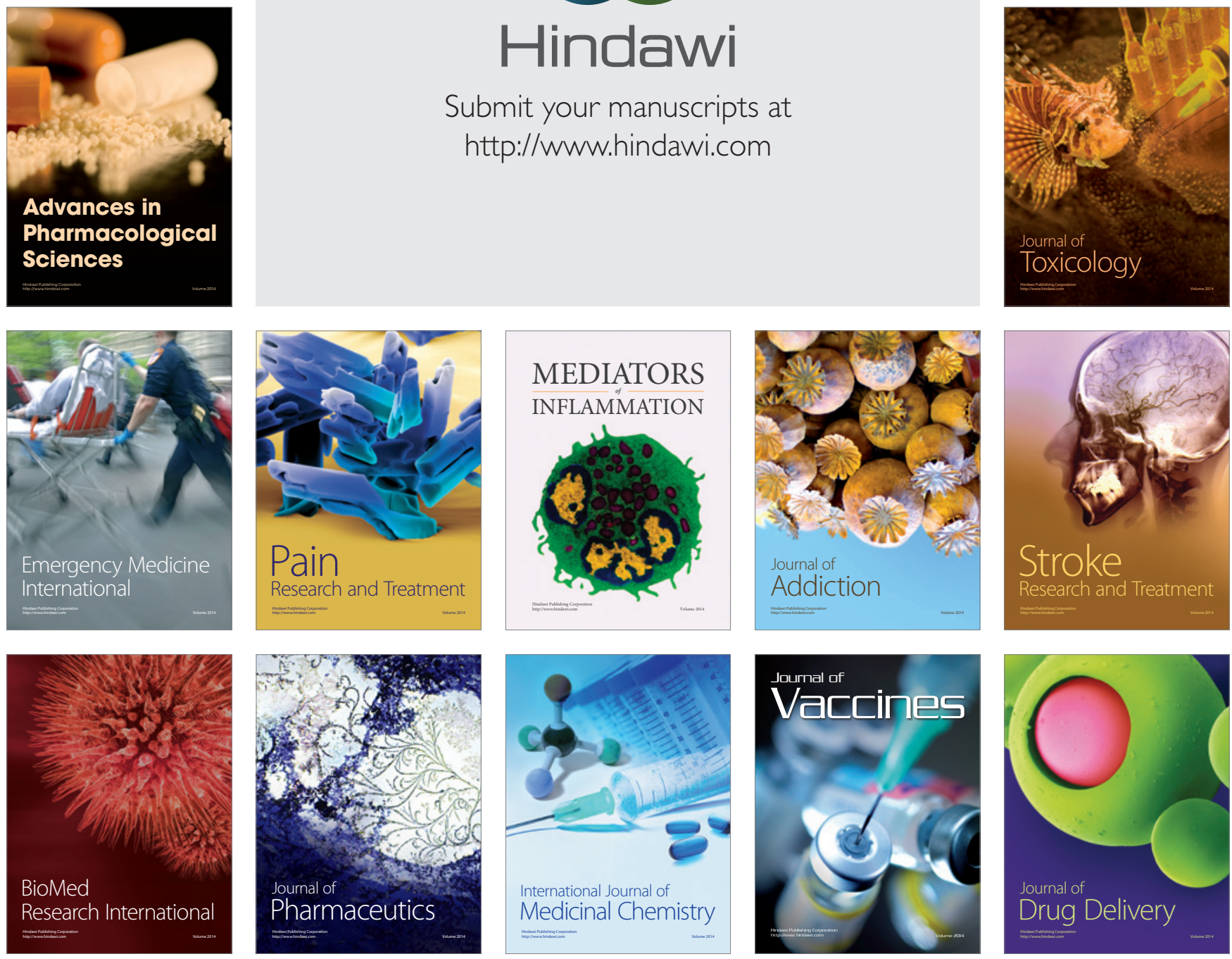